\title{
Investigating the Effect of Using Waste Ultra-high-molecular- weight Polyethylene on the Fatigue Life of Asphalt Mixture
}

\author{
Gholam Hossein Hamedi ${ }^{1 *}$, Mohammad Hadizadeh Pirbasti ${ }^{1}$ Zahra Ranjbar Pirbasti ${ }^{1}$ \\ 1 Department of Civil Engineering, Faculty of Engineering, University of Guilan, P. O. B. 3756, Rasht, Iran \\ *Corresponding author, e-mail: hamedi@guilan.ac.ir
}

Received: 30 April 2020, Accepted: 23 July 2020, Published online: 08 September 2020

\begin{abstract}
One of the effective parameters in the occurrence of fatigue cracking distress is the asphalt binder properties used, which must be controlled by appropriate asphalt binder or additives. In this study, the effect of using Ultra-High-Molecular-Weight Polyethylene (UHMWPE) was investigated on the fatigue cracking potential of asphalt mixtures. Two types of aggregates, asphalt binder performance grade (PG) 64-16, and UHMWPE additive in two percent of the asphalt binder were used in this study, which were tested at two temperatures and five different stress levels. Marshall mix design and indirect tensile fatigue test (ITFT) were used to determine the optimum content of the asphalt binder and the fatigue life of asphalt mixtures, respectively. The results of this study indicated that the application of polymer additives increased the fatigue life of the asphalt mixtures. The fatigue life of specimens made with granite aggregates was longer than those made with limestone aggregates, and the increased life due to the use of UHMWPE was longer in samples made with granite aggregates. As expected, increasing in temperature and stress levels reduced the fatigue life of the asphalt mixtures. This decrease was much lower in samples made of asphalt binder modified with polymeric materials than in control samples. Keywords

asphalt mixtures, fatigue cracking, asphalt binder modification, ultra-high-molecular-weight polyethylene, indirect tensile fatigue test
\end{abstract}

\section{Introduction}

Asphalt mixture layers as the surfaces that are subjected to repeated loading must be sufficiently resistant to fatigue, low temperature cracking, rutting, and moisture damage. The stiffness modulus and fatigue life are the two important parameters for predicting pavement resistance to fatigue cracking [1-3]. When an asphalt concrete is subjected to traffic loads and environmental condition, the compressive stress and strain are formed beneath the wheel at the pavement surface, and the tensile stress and strain are formed at the wheel edges at the pavement surface as well as under the wheel at the lowest level of the asphalt layer [4]. Over time, with repeated loading, as the strain or stress values exceed the strength of the asphalt concrete, cracks occur on the surface and beneath the asphalt mixture layer. These cracks propagate gradually over time and spread to the layer [5].

In recent years, various methods have been used by researchers to improve the rheological properties of asphalt binder and modelling of asphalt binders performance. The use of suitable additives is a way to improve the performance properties of asphalt binder. Until now, common additives such as polymer additives and waxes have been used to modify asphalt binder behavior at high and low temperatures [6]. Although the asphalt binder weight in asphalt mixtures is negligible, much of the studies in the field of asphalt mixtures are about asphalt binder $[7,8]$. Asphalt binder has an important effect on the performance, durability, and stability of asphalt mixtures, and any change in the asphalt binder performance will affect the performance of asphalt mixtures. Preliminary studies on the properties of waste materials showed that these materials can be incorporated into asphalt mixtures as asphalt binder modifier [9].

In many countries, the environment is a major factor influencing the decision-making process for highway construction projects. The benefits of a different asphalt concrete for roads from an environmental and energy perspective are just one important part of the decision-making process. Environmental perspectives accelerate technical and social developments. Multiple environmental 
protection requirements, including limiting greenhouse gas emissions, lower energy consumption, reducing traffic noises, and ensuring safe and comfortable driving are goals that are more important than all scientific advances because of shared responsibility. One of these, for instance, is the closure of the material cycle or the use of 100 percent recyclable materials in road construction. The related industries have gained a lot of experience in the use of by-products in asphalt mixtures. Global shift toward green construction has resulted in an increased focus on the use of recycled plastic waste for asphalt binder modification. However, the successful use of these products depends on thorough research on their resources and properties, which has been done at a low level. It is also possible to continuously study the performance of the asphalt, which is itself a subject of debate [10].

Road construction has significant potential for the use of waste materials because more material is always needed. Recycling is one of the most important and undeniable ways to create a sustainable environment. Almost all materials used by humans (including metals, concrete, plastics, and even glass) should be discarded when they expire, and recycling these materials is the best way to prevent problems from discarding them, which reduces the need for new materials and the space required for storage. It should also be noted that it is not easy to store and dispose of the plastics. The main reason for this is that they are indestructible [11]. Polymers are one of the materials that can be reused as a suitable additive for asphalt binder modification in the pavement industry. Polymers, like other modifiers, have advantages and disadvantages, but the effort is to bring the asphalt binder properties closer to ideal properties, depending on the conditions used. For this purpose, Ultra-High-Molecular-Weight Polyethylene (UHMWPE) as recycling from the battery industry, was used in this study due to its positive effects, such as increased resistance to high temperature, resistance to aging, increased stiffness modulus, and low cost for asphalt binder modification.

\subsection{Literature review}

Silva et al. [12] studied the mechanical properties of modified asphalt mixtures with $4-6 \%$ by weight of bitumen from PET polymer and compared with control asphalt mixtures. The results presented in this study show that the use of this material has improved the fatigue life, stiffness modulus and strength against the rutting of modified asphalt mixtures compared to control samples.
Ghile [13] increased the life of the asphalt specimens two times by adding 2 percent nanoclay at $20^{\circ} \mathrm{C}$, but at $5^{\circ} \mathrm{C}$, the nanoclay had a negative effect on the asphalt mixture life and reduced it by 20 percent. Hamedi [14] increased the life of the asphalt specimens 1.7 times by adding $7 \%$ nanoclay at $25^{\circ} \mathrm{C}$. On the other hand, You et al. [15] found that nanoclay increased 50 to $100 \%$ viscosity and $65 \%$ to $200 \%$ stiffness of asphalt by performing rotational viscometer and dynamic shear rheometer tests on control and modified samples with $2 \%$ and $4 \%$ nanoclay, respectively. Besides, Liu [16] showed that at lower stress levels, the fatigue life of the modified asphalt mixture increased by up to $40 \%$, but at higher stress levels, there was not a significant increase in fatigue life. Xiao et al. [17, 18] evaluated the effect of carbon nanoparticles on the rheological properties of aged asphalt binder by rolling thin film oven (RTFO) and pressure aging vessel (PAV) tests. The results showed that adding $1.5 \%$ carbon nanoparticles to asphalt binder caused a $60 \%$ increase in rutting resistance, but statistical analysis indicated that the asphalt binder type had more impact on fatigue behavior of asphalt binder than nanoparticle percentage changes. Khattak et al. [19] investigated the effect of carbon nanofibers on the rheology of asphalt binder. The researchers found that carbon nanofibers improved the mechanical properties of asphalt binder by forming a solid network in asphalt binder, and somehow, prevents the propagation of micro-cracks by sewing the early cracks. The results showed that the fatigue parameter $\left(G^{*} \sin \delta\right)$ of the modified asphalt binder increased 2 to 3 times at $20{ }^{\circ} \mathrm{C}$ by using $2 \%$ and $2.5 \%$ carbon nanofibers. Also, the rutting parameter $\left(G^{*} \sin \delta\right)$ was increased 2 times by the addition of carbon nanofibers. Azarhoosh et al. [20] used asphalt binder with a penetration rate of $85 / 100$ and Nano lime as its modifier. The results showed that using Nano lime increases the free energy of cohesion and adhesion and, therefore, improves mix asphalt resistance against fatigue cracks in the asphalt binder membrane and the interface of the asphalt binder and aggregate, respectively. In addition, the results of an indirect tensile fatigue test indicated that mix asphalt modified with Nano lime has a greater fatigue life than control mix asphalt in both dry and wet conditions

\subsection{Statement and objectives}

The main purpose of the present study is to investigate the effect of asphalt binder modification using UHMWPE polymeric material on different properties of asphalt mixtures against fatigue cracking. Therefore, it has been 
attempted to make asphalt mixtures optimally resistant to loading by modifications in materials used in asphalt mixtures. The most important objectives of this study were:

- Investigating the fatigue behavior of the asphalt mixtures made with waste UHMWPE-modified asphalt binder

- Investigating the effect of aggregate type on the fatigue life of asphalt mixtures modified by waste UHMWPE

- Studying the effect of waste UHMWPE content on the fatigue life of different asphalt mixtures

- Examining the effect of changes in temperature and stress intensity on the fatigue life of asphalt mixtures modified by waste UHMWPE

\section{Materials and methods}

\subsection{Materials}

The chemical compounds and the physical properties of these aggregates are presented in Table 1 and Table 2, respectively.

The aggregate gradation used in this study was according to the ASTM standard with nominal maximum aggregate size with $12.50 \mathrm{~mm}$, which is shown in Fig. 1.

UHMWPE is a type of polyethylene obtained through low pressure and the use of the Ziglernata catalyst and has a linear structure. The material used in this study is a waste from the battery manufacturing industry that has been

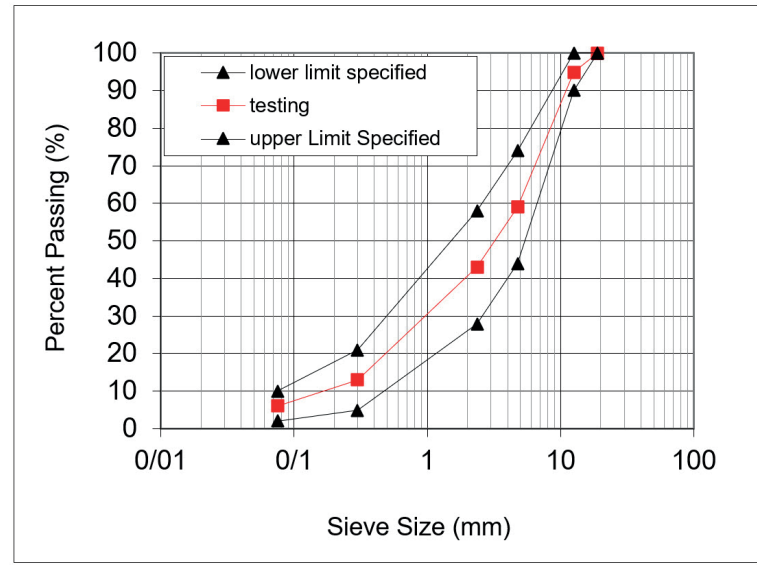

Fig. 1 Gradation curves of the aggregates used in the study

reconstituted as a raw material with a polymer mill. It is in the form of very fine solid particles about $150-120 \mu \mathrm{m}$. This material has unique properties including:

- High skid resistance

- High impact resistance

- Low moisture absorption

- Excellent crack resistance

- High energy absorber, and

- Excellent sound damper

Another prominent feature of UHMWPE is its storage between temperatures of $90-269{ }^{\circ} \mathrm{C}$ or even higher temperatures in the short periodic time. Unlike low-molecular-weight polyethylene, the melt viscosity is very

Table 1 Chemical compound of the aggregates

\begin{tabular}{|c|c|c|c|c|c|c|}
\hline Aggregate & Calcium oxide & Magnesium oxide & Ferric oxide & Aluminium oxide & $\mathrm{Al}_{2} \mathrm{O}_{3}+\mathrm{Fe}_{2} \mathrm{O}_{3}$ & Silicon dioxide \\
\hline Limestone & 51.3 & 1.2 & 0.4 & 2.3 & 18 & 3.8 \\
\hline Granite & 2.4 & 0.8 & 1.4 & 4.8 & 16.2 & 68.1 \\
\hline
\end{tabular}

Table 2 Physical properties of the aggregates

\begin{tabular}{|c|c|c|c|c|}
\hline Property & Standard & Granite & Limestone & Specification \\
\hline \multicolumn{5}{|l|}{ Specific gravity (coarse agg.) } \\
\hline Bulk & \multirow{3}{*}{ ASTM C 127 [21] } & 2.654 & 2.612 & ----- \\
\hline Saturated-surface-dry (SSD) & & 2.667 & 2.643 & ---- \\
\hline Apparent & & 2.692 & 2.692 & ----- \\
\hline \multicolumn{5}{|l|}{ Specific gravity (fine agg.) } \\
\hline Bulk & \multirow{3}{*}{ ASTM C 128 [22] } & 2.659 & 2.618 & ---- \\
\hline Saturated-surface-dry (SSD) & & 2.661 & 2.633 & ---- \\
\hline Apparent & & 2.688 & 2.688 & ----- \\
\hline Specific gravity (filler) & ASTM D854 [23] & 2.656 & 2.656 & ---- \\
\hline Los Angeles abrasion (\%) & ASTM C131 [24] & 19 & 25.6 & $\operatorname{Max} 45$ \\
\hline Coarse Aggregate Angularity & ASTM D5821 [25] & 94.5 & 97 & Least 90 \\
\hline Flat and elongated particles (\%) & ASTM D $4791[26]$ & 6.5 & & Max 10 \\
\hline Fine Aggregate Angularity & ASTM C 1252 [27] & 56.3 & 58.9 & Least 40 \\
\hline
\end{tabular}


high, and its non-fluid behavior is very high due to the high degree of cross-linking in the chains. UHMWPE is a high molecular weight material because it has excellent mechanical properties such as high impact resistance and good chemical resistance and good chemical resistance as well as low wrinkle rate, so it can be used as a separator. Can be used. In this study, the waste of this material was used as bitumen modifier. Asphalt binder is one of the most commonly used building materials because of its two important properties, waterproofing, and adhesion. In this study, the asphalt binder with PG 64-16 was used, provided by Isfahan Refinery. The specifications of asphalt binder are presented in Table 3.

\subsection{Number of specimens}

In this study, different combinations of asphalt mixtures were used with different fatigue cracking potentials. Therefore, the materials used in this study include two types of aggregates with different mineralogical structure, base asphalt binder with PG 64-16 along with UHMWPE additive as the asphalt binder modifier in two percent of the asphalt binder mass. Since comparing different asphalt specimens without considering various parameters affecting their mechanical and resistive properties seems unreasonable, in this study the optimum asphalt binder content for each mix design was determined, and after making each specimen with its optimum asphalt binder content, the results in the optimum conditions of this specimen were compared with the optimum conditions of the other specimens. Number of asphalt mixtures for optimum asphalt binder content and moisture sensitivity tests are presented in Table 4.
Table 3 Specification of the asphalt binder

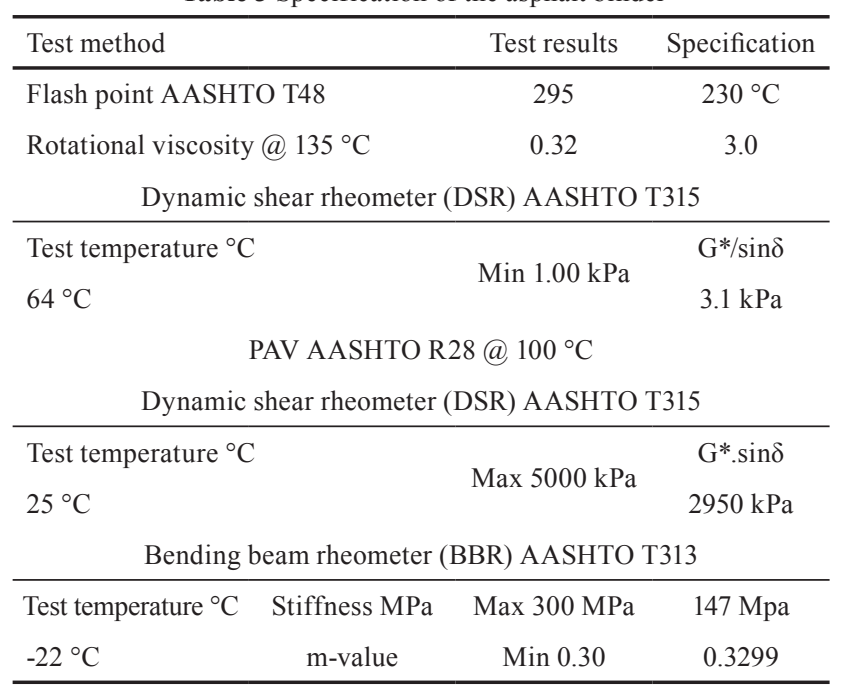

Six different combinations of asphalt mixtures were created by mixing the materials mentioned above. Considering temperatures of 5 and $20^{\circ} \mathrm{C}$ and stress levels of $100,200,300,400$, and $500 \mathrm{kPa}$ for each combination, there were 10 temperature modes. A total of 120 specimens were made assuming 2 replicates for each test. Also, 60 specimens were made to determine the optimum content of the asphalt binder for control mixtures. It should be noted that the optimum content of the asphalt binder was only in the specimens with control asphalt binder so that the asphalt binder percentage did not differ among the specimens with similar aggregates. The different temperature and stress modes for each combination are listed in Table 5.

Table 4 Number of asphalt mixtures for optimum asphalt binder content and moisture sensitivity tests

\begin{tabular}{|c|c|c|c|c|}
\hline Type of aggregate & Target & Test & Asphalt binder type & Number of specimens \\
\hline Granite & $\begin{array}{l}\text { Determination of the optimum } \\
\text { asphalt binder content }\end{array}$ & Marshall mix design & Control asphalt binder & 30 \\
\hline Limestone & $\begin{array}{l}\text { Determination of the optimum } \\
\text { asphalt binder content }\end{array}$ & Marshall mix design & Control asphalt binder & 30 \\
\hline Granite & Determining the fatigue life & $\begin{array}{l}\text { Repeated indirect tensile loading at } \\
10 \text { stress levels and two temperatures }\end{array}$ & Control asphalt binder & 20 \\
\hline ॠLimestone & Determining the fatigue life & $\begin{array}{l}\text { Repeated indirect tensile loading at } \\
10 \text { stress levels and two temperatures }\end{array}$ & Control asphalt binder & 20 \\
\hline Granite & Determining the fatigue life & $\begin{array}{l}\text { Repeated indirect tensile loading at } \\
10 \text { stress levels and two temperatures }\end{array}$ & $\begin{array}{l}\text { Asphalt binder modified } \\
\text { with } 2 \% \text { UHMWPE }\end{array}$ & 20 \\
\hline Limestone & Determining the fatigue life & $\begin{array}{l}\text { Repeated indirect tensile loading at } \\
10 \text { stress levels and two temperatures }\end{array}$ & $\begin{array}{l}\text { Asphalt binder modified } \\
\text { with } 2 \% \text { UHMWPE }\end{array}$ & 20 \\
\hline Granite & Determining the fatigue life & $\begin{array}{l}\text { Repeated indirect tensile loading at } \\
10 \text { stress levels and two temperatures }\end{array}$ & $\begin{array}{l}\text { Asphalt binder modified } \\
\text { with 4\% UHMWPE }\end{array}$ & 20 \\
\hline Limestone & Determining the fatigue life & $\begin{array}{l}\text { Repeated indirect tensile loading at } \\
10 \text { stress levels and two temperatures }\end{array}$ & $\begin{array}{l}\text { Asphalt binder modified } \\
\text { with 4\% UHMWPE }\end{array}$ & 20 \\
\hline
\end{tabular}


Table 5 Different loading modes of fatigue life for each combination of asphalt mixture

\begin{tabular}{|c|c|c|c|c|}
\hline $\begin{array}{l}\text { Type of } \\
\text { aggregate }\end{array}$ & $\begin{array}{l}\text { Asphalt binder } \\
\text { type }\end{array}$ & $\begin{array}{l}\text { Stress } \\
(\mathrm{kPa})\end{array}$ & $\begin{array}{c}\text { Temperature } \\
\left({ }^{\circ} \mathrm{C}\right)\end{array}$ & $\begin{array}{c}\text { Number of } \\
\text { samples }\end{array}$ \\
\hline Granite & $\begin{array}{c}\text { Control } \\
\text { Asphalt binder }\end{array}$ & 100 & 5 & 2 \\
\hline Granite & $\begin{array}{c}\text { Control } \\
\text { Asphalt binder }\end{array}$ & 200 & 5 & 2 \\
\hline Granite & $\begin{array}{c}\text { Control } \\
\text { Asphalt binder }\end{array}$ & 300 & 5 & 2 \\
\hline Granite & $\begin{array}{c}\text { Control } \\
\text { Asphalt binder }\end{array}$ & 400 & 5 & 2 \\
\hline Granite & $\begin{array}{c}\text { Control } \\
\text { Asphalt binder }\end{array}$ & 500 & 5 & 2 \\
\hline Granite & $\begin{array}{c}\text { Control } \\
\text { Asphalt binder }\end{array}$ & 100 & 20 & 2 \\
\hline Granite & $\begin{array}{c}\text { Control } \\
\text { Asphalt binder }\end{array}$ & 200 & 20 & 2 \\
\hline Granite & $\begin{array}{c}\text { Control } \\
\text { Asphalt binder }\end{array}$ & 300 & 20 & 2 \\
\hline Granite & $\begin{array}{c}\text { Control } \\
\text { Asphalt binder }\end{array}$ & 400 & 20 & 2 \\
\hline Granite & $\begin{array}{c}\text { Control } \\
\text { Asphalt binder }\end{array}$ & 500 & 20 & 2 \\
\hline
\end{tabular}

\subsection{Experimental procedure}

\subsubsection{Marshall mix design according to ASTM D1559}

In this study, the Marshall mix design was used to determine the optimum content of the asphalt binder. The optimum content of the asphalt binder diagrams should be plotted for the base combination. The optimum asphalt binder was determined according to structure of Manual Series-2 of Asphalt Institute.

\subsubsection{Fatigue test}

The fatigue life of the asphalt mixtures was obtained by indirect tensile fatigue test (ITFT). The ITFT is a type of fatigue test in which the load is repeatedly applied to a cylindrical specimen so that the compressive load is applied to the sides of the cylinder parallel and vertically. This form of loading causes uniform tensile stress in the specimen that is perpendicular to the direction of loading and along the longitudinal axis of the cylindrical specimen. The loading mode in the fatigue test is in two ways: stress control and strain control. In the stress control mode, the stress level remains constant throughout the test. In this loading mode, it is easy to define the fracture condition because the specimen breaks at the end of the test. In the strain control mode, the strain level is kept constant during the test. The exact definition of fracture in the form of a constant strain is difficult to define because the stress must be reduced to maintain the strain constant during the test. As a result, after many cycles, the stress drops to a very low level, and the sample fracture becomes difficult. Some researchers have defined failure at constant strain as a $50 \%$ reduction in initial stiffness, and others a $50 \%$ reduction in stress or initial force [28].

The relationship between tensile strain and the number of cycles leading to failure can be plotted by having a certain tensile strain for any stress levels. As a result of applying the vertical compressive stresses in the fatigue test, indirect tensile stress and strain occur horizontally, and repeated loading will eventually lead to vertical cracking in the center of the specimen. Loading in the fatigue test, as well as the stiffness modulus test, is linear along the axis of the sample diameters. The relationships and parameters related to fatigue, including fatigue life and the number of cycles required for fatigue cracking are determined by ITFT [28].

A cognitive phenomenon associated with the initial response (such as tensile stress) of an asphalt mixture during fatigue life is one of the most commonly used application of fatigue models. This phenomenological model is easily applicable because it only requires measuring the fatigue response of fatigue tests at different stress levels [29]. The fatigue characteristics and properties of the material, as a relationship between the applied stress and the number of loading repetitions to fracture, are described as follows:

$N_{f}=K_{1}\left(\frac{1}{\sigma}\right)^{K_{2}}$,

where, $N_{f}$ is the number of loading repetitions leading to fracture, $\sigma$ is the applied stress, and $K_{1}$ and $K_{2}$ are the test constants. Laboratory studies showed that these constants depend on different properties of the asphalt mixture, such as stiffness, air void, asphalt binder content, and the size of aggregates.

In this study, the fatigue life of the specimens was measured by the stress control method. Repeated loading was applied to the specimens with $0.1 \mathrm{~s}$ loading and $0.4 \mathrm{~s}$ rest time. Also, cylindrical specimens (101.6 $\mathrm{mm}$ in diameter and $40 \mathrm{~mm}$ in height) and $100,200,300,400$, and $500 \mathrm{kPa}$ stress levels at $5^{\circ} \mathrm{C}$ and $20{ }^{\circ} \mathrm{C}$ were used to evaluate the fatigue behavior of the asphalt mixtures.

The setup and loading of the specimen into the NAT device in the fatigue test and an overview of the Nottingham machine software settings page for fatigue testing is shown in Figs. 2 and 3. 


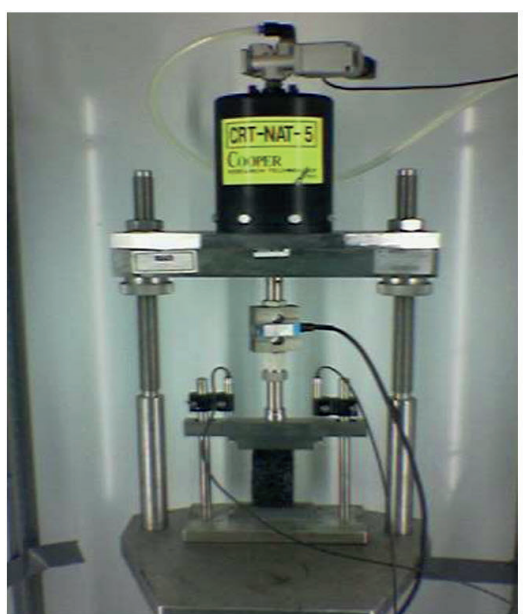

Fig. 2 Samples loading in the fatigue test

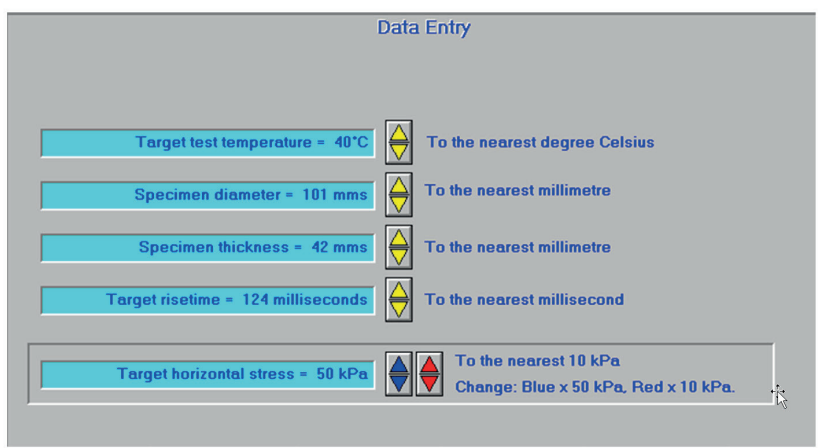

Fig. 3 Fatigue test software settings page [30]

\section{Results and discussion}

This section describes the results of performed tests on the asphalt mixtures. First, the results of the Marshall mix design are presented to determine the optimum content of the asphalt binder. Then, the results of the repetitive loading test using the indirect tensile strength test are presented to investigate the effect of the additives used in this study.

\subsection{The results of the marshall test on the control specimens}

The optimum content of the asphalt binder for each mix (including two types of granite and limestone aggregates) was determined by Marshall test for scientific and rational comparison of the results of performed tests on the control and modified asphalt specimens. The asphalt specimens then were constructed under different conditions with the optimum content of the asphalt binder. Specimens containing limestone had a higher asphalt binder content than samples containing granite. This is due to the higher porosity of the limestone aggregate surfaces and higher asphalt binder absorption of these types of aggregates compared to granite aggregates. Based on the procedure mentioned in the previous section, the optimum content of the asphalt binder for samples made with limestone aggregates was determined $5.7 \%$. These results are presented in Table 6 .

The values corresponding to the five parameters of stability, flow, air void (AV), voids in menral aggregates (VMA), and voids fill with asphalt binder (VFA) must be controlled by the specification after determining the optimum content of the asphalt binder. The results are presented in the Table 7. As can be seen, the optimum content of the asphalt binder met all requirements.

The optimum content of the asphalt binder for samples made with granite aggregates was determined $5.5 \%$. It can be seen that the optimum content of the asphalt binder in these specimens was lower than those made with limestone aggregates. This is because of the lower porosity of the granite aggregates, which reduces the absorption of useless asphalt binder. These results are presented in Table 8 .

The values corresponding to the five parameters of stability, flow, AV, VMA, and VFA must be controlled by the specification after determining the optimum content

Table 6 Optimum content of the asphalt binder (limestone)

\begin{tabular}{lc}
\hline Type of aggregate & Limestone \\
\hline $\begin{array}{l}\text { The percentage of asphalt binder corresponding to } \\
\text { maximum stability }\end{array}$ & 5.7 \\
$\begin{array}{l}\text { The percentage of asphalt binder corresponding to } \\
\text { 4\% air void }\end{array}$ & 5.6 \\
$\begin{array}{l}\text { The percentage of asphalt binder corresponding to } \\
\text { maximum unit weight }\end{array}$ & 5.8 \\
Optimum asphalt binder percentage & 5.7 \\
\hline
\end{tabular}

Table 7 Control of parameters corresponding to the optimum content of the asphalt binder (limestone)

\begin{tabular}{lcc}
\hline Optimum content of the asphalt binder & Specification & 5.7 \\
\hline Stability & At least 800 & 1030 \\
Flow & $2-3.5$ & 2.7 \\
AV & $3-5$ & 3.9 \\
VMA & at least 14 & 14.5 \\
VFA & $60-75$ & 72 \\
\hline
\end{tabular}

Table 8 Optimum content of the asphalt binder (granite)

\begin{tabular}{lc}
\hline Type of aggregate & Granite \\
\hline $\begin{array}{l}\text { The percentage of asphalt binder corresponding to } \\
\text { maximum stability }\end{array}$ & 5.6 \\
$\begin{array}{l}\text { The percentage of asphalt binder corresponding to } \\
\text { 4\% air void }\end{array}$ & 5.5 \\
$\begin{array}{l}\text { The percentage of asphalt binder corresponding to } \\
\text { maximum unit weight }\end{array}$ & 5.5 \\
Optimum asphalt binder percentage & 5.5 \\
\hline
\end{tabular}


Table 9 Control of parameters corresponding to the optimum content of the asphalt binder (granite aggregates)

\begin{tabular}{lcc}
\hline Optimum content of the asphalt binder & Specification & 5.5 \\
\hline Stability & At least 800 & 1020 \\
Flow & $2-3.5$ & 2.7 \\
AV & $3-5$ & 4 \\
VMA & at least 14 & 14.2 \\
VFA & $60-75$ & 74 \\
\hline
\end{tabular}

of the asphalt binder. The results are presented in Table 9. As can be seen, the optimum content of the asphalt binder met all requirements.

\subsection{Results of the fatigue test}

\subsubsection{Results of the fatigue test in specimens made with granite aggregate}

Figs. 4 and 5 show the number of loading cycles leading to the fracture of the control specimens and UHMWPEmodified asphalt specimens made with granite aggregates.

The results indicated that the asphalt specimens modified with UHMWPE had a significantly better fatigue performance compared to the control specimens. The carbon

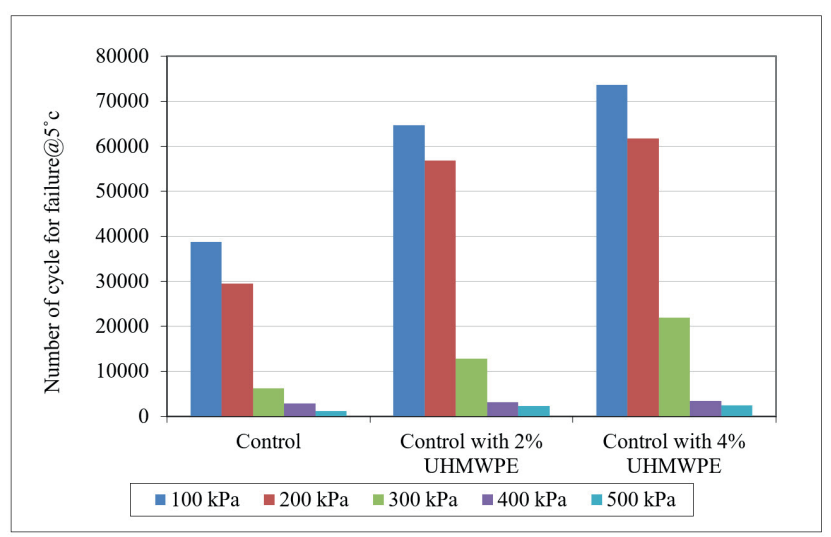

Fig. 4 Number of loading cycles in the fatigue test at $5{ }^{\circ} \mathrm{C}$ (granite)

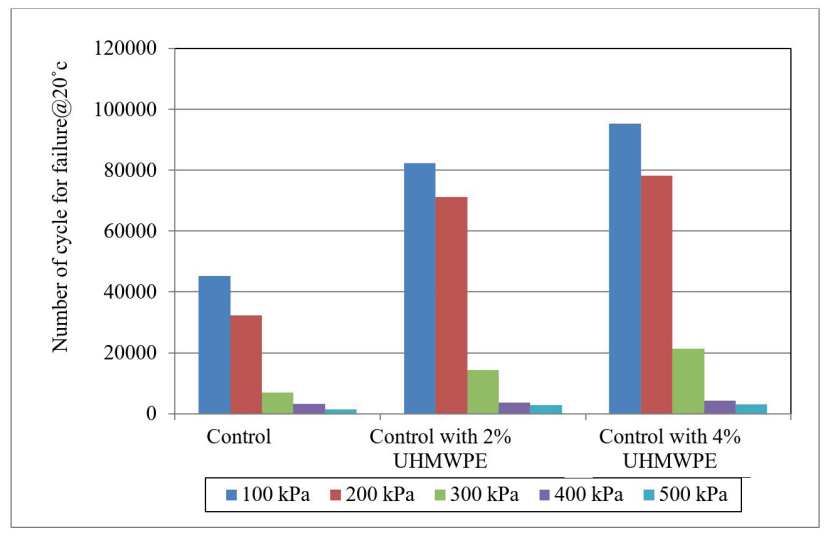

Fig. 5 Number of loading cycles in the fatigue test at $20^{\circ} \mathrm{C}$ (granite) released by the mixing of asphalt binder with UHMWPE forms strong bonds with the asphalt binder chains by filling the voids, which increases the adhesion of asphalt binder the o the aggregate. This better adhesion between the aggregates also minimizes the displacement of the aggregate particles, thus improves the fatigue life due to the delay in the formation and propagation of crack. Besides, any remaining UHMWPE particles that do not enter the chemical reaction can complete the gradation of the filler materials and cover the fine-grained part of the gradation curve. As a result, it can increase the fatigue life of the asphalt mixtures by reducing the air voids. On the other hand, adding UHMWPE to the asphalt binder increases its stiffness. If the stress level is constant in the fatigue test, as the stiffness of the specimens increases, the tensile strain decreases, and the corresponding fatigue life is increased.

In addition, the fatigue life of the asphalt specimens decreases as the temperature increases. This is due to the high sensitivity of the elastic modulus of asphalt specimens to the temperature changes. Therefore, the fatigue life of the specimens is reduced under cyclic loading by increasing the temperature and thus reducing the elastic modulus of the specimens.

The results of these two sets of graphs indicated that the application of higher stress levels reduced the fatigue life of the specimens. In fact, an increase in stress level increased the tensile strain in the specimens, which reduced the fatigue life of the asphalt mixtures. It should be noted that the increase in stress level from 200 to $300 \mathrm{kPa}$ greatly reduced fatigue life of all specimens.

The results of the fatigue life at $5{ }^{\circ} \mathrm{C}$ demonstrated that the application of UHMWPE had significantly increased the fatigue life of the asphalt mixtures. This increase was more pronounced in specimens made with two percent of the additive compared to the control specimens.

Figs. 6 and 7 compared the results of the fatigue tests in control and UHMWPE-modified specimens. In these figures, regression lines were drawn across the specimens at each stress level. The results demonstrated that there was an appropriate linear relationship between the logarithm of stress and the logarithm of the fatigue life. The analysis of fatigue results showed a significant improvement in the life of the UHMWPE-modified mixtures.

The fatigue equation, the values of $K_{1}$ and $K_{2}$, and the correlation coefficients for each mixture are given in Table 10. 


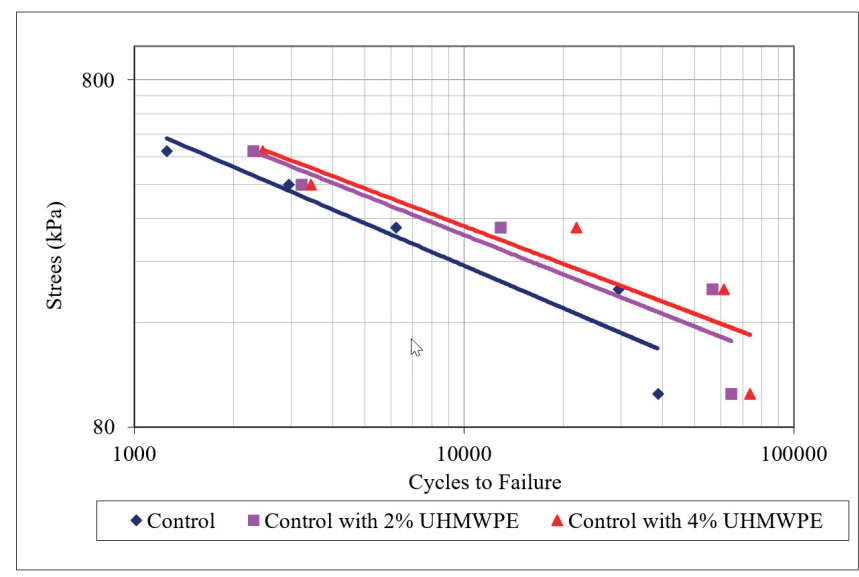

Fig. 6 The fatigue behavior of mixtures at $5^{\circ} \mathrm{C}$ (granite)

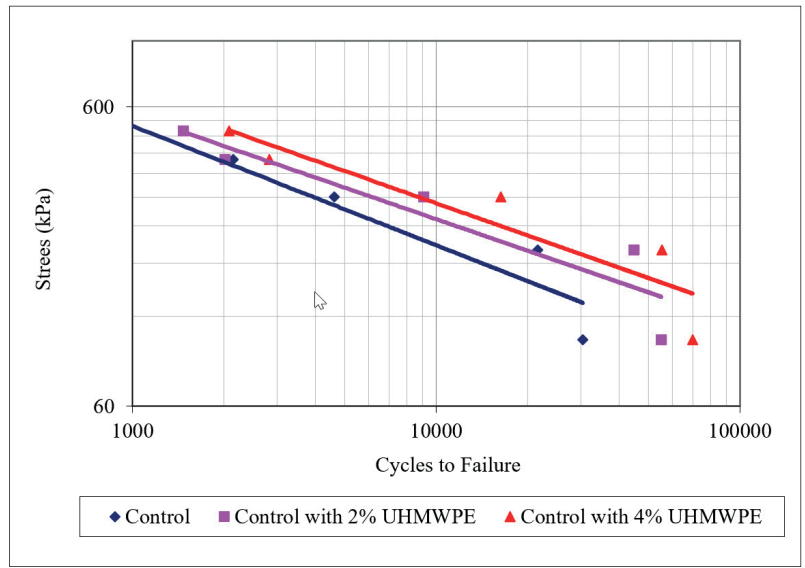

Fig. 7 The fatigue behavior of mixtures at $20^{\circ} \mathrm{C}$ (granite)

Table 10 Fatigue equations and fatigue coefficients in control and UHMWPE-modified specimens (granite)

\begin{tabular}{|c|c|c|c|c|c|c|}
\hline & Type of mixture & Test temperature & Fatigue equation & $K_{1}$ & $K_{2}$ & $R_{2}$ \\
\hline 1 & Control & 5 & $N_{f}=9873 \sigma^{-0.406}$ & 9873 & 0.406 & 0.8875 \\
\hline 2 & Base asphalt binder with $2 \%$ UHMWPE & 5 & $N_{f}=9209 \sigma^{-0.377}$ & 9209 & 0.377 & 0.8525 \\
\hline 3 & Base asphalt binder with $4 \%$ UHMWPE & 5 & $N_{f}=8452 \sigma^{-0.361}$ & 8452 & 0.361 & 0.8174 \\
\hline 4 & Control & 20 & $N_{f}=8110 \sigma^{-0.398}$ & 8110 & 0.398 & 0.8949 \\
\hline 5 & Base asphalt binder with $2 \%$ UHMWPE & 20 & $N_{f}=6336 \sigma^{-0.35}$ & 6336 & 0.35 & 0.859 \\
\hline 6 & Base asphalt binder with $4 \%$ UHMWPE & 20 & $N_{f}=7672 \sigma^{-0.357}$ & 7672 & 0.357 & 0.847 \\
\hline
\end{tabular}

\subsubsection{Results of the fatigue test in specimens made with limestone aggregate}

Figs. 8 and 9 show the number of loading cycles leading to the fracture of the control and UHMWPE-modified limestone specimens. As can be seen, specimens made with limestone aggregates generally had less fatigue life than those made with granite aggregates.

The results indicated that similar to those specimens made with granite aggregates, UHMWPE-modified specimens exhibited significantly better fatigue performance

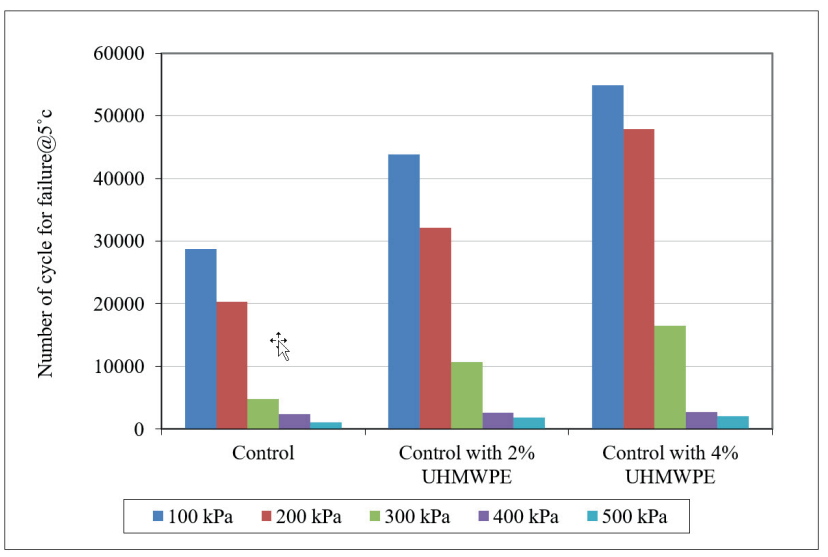

Fig. 8 Number of loading cycles in the fatigue test at $5^{\circ} \mathrm{C}$ (specimens made with limestone aggregates) compared to control specimens. The notable difference in these specimens was that the application of $4 \%$ polymeric material in comparison with $2 \%$ polymeric material made a significant difference, which was not significant in the specimen made with granite aggregates. For example, at the $100 \mathrm{kPa}$ stress level, the fatigue life in the control specimens and specimens modified with $2 \%$ and $4 \%$ UHMWPE were 28693, 43836 and 54882 cycles, respectively. This procedure was also observed at high levels of stress. For instance, at a stress level of $500 \mathrm{kPa}$

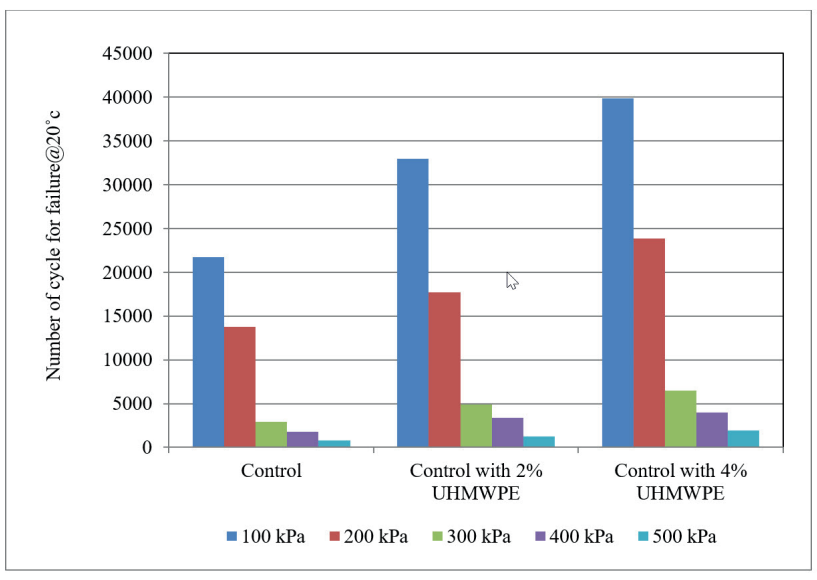

Fig. 9 Number of loading cycles in the fatigue test at $20^{\circ} \mathrm{C}$ (specimens made with limestone aggregates) 
and a temperature of $20{ }^{\circ} \mathrm{C}$, the fatigue life in the control specimens was 789 cycles, which reached 1218 and 1974 as a result of using $2 \%$ and $4 \%$ UHMWPE material, respectively.

Similar to those specimens made with granite aggregates, the fatigue life of the limestone specimens decreased as temperature increased. The fatigue life reduction was lower in specimens made with limestone aggregates than those made with granite aggregates.

Figs. 10 and 11 compared the results of fatigue tests on the control and UHMWPE-modified specimens. The results demonstrated that there was an appropriate linear relationship between the logarithm of stress and the logarithm of the fatigue life. The analysis of fatigue results showed a significant improvement in the life of the UHMWPE mixtures.

The fatigue equation, the values of $K_{1}$ and $K_{2}$, and the correlation coefficients for mixtures are given in Table 11.

\section{Conclusions}

In this study, the improvement of the fatigue life of the asphalt mixtures was investigated using waste UHMWPE as an asphalt binder modifier. The following important conclusions are drawn from this study:

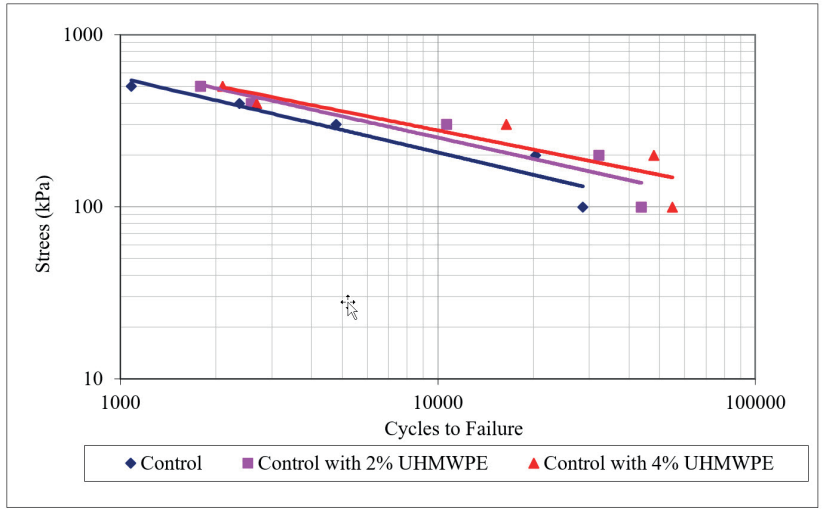

Fig. 10 The fatigue behavior of mixtures at $5^{\circ} \mathrm{C}$ (specimens made with limestone aggregates)
- Specimens made with limestone aggregates had a higher optimum content of the asphalt binder in comparison with similar specimens made with granite aggregates. This is mainly because of the higher surface porosity of the limestone aggregates than granite ones.

- An increase in stress level reduced the fatigue life of the asphalt mixtures. The reduction of the fatigue life of specimens was very significant at 300 and $200 \mathrm{kPa}$ stress levels.

- Increasing the temperature decreased the stiffness modulus of the asphalt mixtures, which caused the tensile strain in the asphalt mixture to be increased at high temperatures and the fatigue life to be greatly reduced.

- The application of the UHMWPE additive reduced the stiffness of the asphalt mixtures. On the other hand, it increased the asphalt binder-aggregate adhesion, which increased the fatigue life and the resistance of the asphalt mixtures to fatigue cracking.

- The application of $2 \%$ UHMWPE significantly improved the fatigue life of the specimens made with granite and limestone aggregates. The difference in fatigue life improvement of the asphalt mixtures

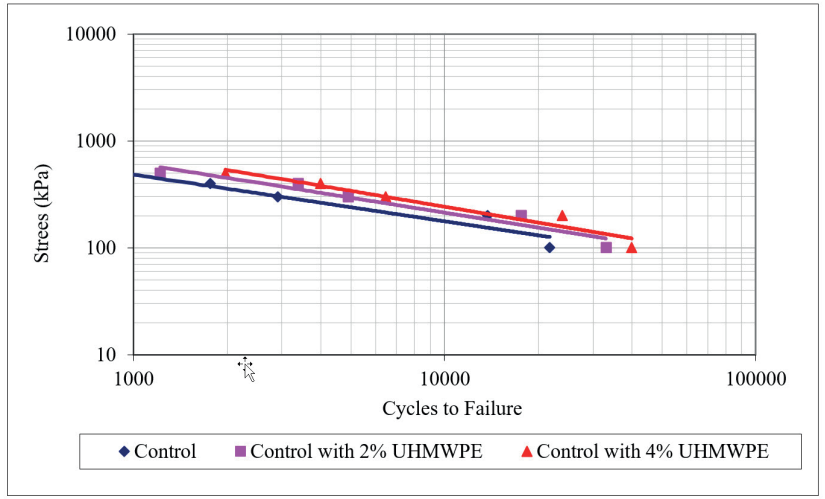

Fig. 11 The fatigue behavior of mixtures at $20{ }^{\circ} \mathrm{C}$ (specimens made with limestone aggregates)

Table 11 Fatigue equations and fatigue coefficients in control and UHMWPE-modified specimens (limestone)

\begin{tabular}{|c|c|c|c|c|c|c|}
\hline & Type of mixture & Test temperature & Fatigue equation & $K_{1}$ & $K_{2}$ & $R_{2}$ \\
\hline 1 & Control & 5 & $N_{f}=1153 \sigma^{-0.433}$ & 1153 & 0.433 & 0.8875 \\
\hline 2 & Base asphalt binder with $2 \%$ UHMWPE & 5 & $N_{f}=11124 \sigma^{-0.411}$ & 11124 & 0.411 & 0.8689 \\
\hline 3 & Base asphalt binder with 4\% UHMWPE & 5 & $N_{f}=8439 \sigma^{-0.37}$ & 8439 & 0.37 & 0.8143 \\
\hline 4 & Control & 20 & $N_{f}=9870 \sigma^{-0.436}$ & 9870 & 0.436 & 0.9188 \\
\hline 5 & Base asphalt binder with $2 \%$ UHMWPE & 20 & $N_{f}=15464 \sigma^{-0.465}$ & 15464 & 0.465 & 0.9207 \\
\hline 6 & Base asphalt binder with 4\% UHMWPE & 20 & $N_{f}=22585 \sigma^{-0.492}$ & 22585 & 0.492 & 0.9349 \\
\hline
\end{tabular}


made with granite aggregates modified with $2 \%$ additive and $0 \%$ additive was greater than the difference in specimens modified with $4 \%$ and $2 \%$ additive. Therefore, an economic analysis must be performed to determine the optimum amount of UHMWPE additive. On the other hand, there was

\section{References}

[1] Moghadas Nejad, F., Azarhoosh, A. R., Hamedi, G. H., Azarhoosh, M. J. "Characterization of permanent deformation resistance of precipitated calcium carbonate modified asphalt mixture", Journal of Civil Engineering and Management, 21(5), pp. 615-622, 2015. https://doi.org/10.3846/13923730.2014.890654

[2] Cho, S., Tóth, Cs., Primusz, P. "Application of the Ramberg-Osgood model in asphalt technology", Journal of Physics: Conference Series, 1527, Article number: 012007, 2020.

[3] Tóth, Cs., Soós, Z., Igazvölgyi, Zs. "Testing and interpreting permeability of asphalt mixes", Građevinar, 72(5), pp. 395-400, 2020. https://doi.org/10.14256/JCE.2532.2018

[4] Moghadas Nejad, F., Azarhoosh, A. R., Hamedi, G. H. "Laboratory Evaluation of Using Recycled Marble Aggregates on the Mechanical Properties of Hot Mix Asphalt", Journal of Materials in Civil Engineering, 25(6), pp. 741-746, 2013.

https://doi.org/10.1061/(ASCE)MT.1943-5533.0000539

[5] Moghadas Nejad, F., Azarhoosh, A. R., Hamedi, G. H. "Effect of high density polyethylene on the fatigue and rutting performance of hot mix asphalt - a laboratory study", Road Materials and Pavement Design, 15(3), pp. 746-756, 2014.

https://doi.org/10.1080/14680629.2013.876443

[6] Hamedi, G. H., Azarhoosh, A. R., Khodadadi, M. "Effects of Asphalt Binder Modifying with Polypropylene on Moisture Susceptibility of Asphalt Mixtures with Thermodynamically Concepts", Periodica Polytechnica Civil Engineering, 62(4), pp. 901-910, 2018. https://doi.org/10.3311/PPci.11570

[7] Azarhoosh, A. R., Hamedi, G. H., Abandansari, H. F. "Providing Laboratory Rutting Models for Modified Asphalt Mixes with Different Waste Materials", Periodica Polytechnica Civil Engineering, 62(2), pp. 308-317, 2018.

https://doi.org/10.3311/PPci.10684

[8] Choudhary, R., Kumar, A., Murkute, K. "Properties of Waste Polyethylene Terephthalate (PET) Modified Asphalt Mixes: Dependence on PET Size, PET Content, and Mixing Process", Periodica Polytechnica Civil Engineering, 62(3), pp. 685-693, 2018.

https://doi.org/10.3311/PPci.10797

[9] Hamedi, G. H., Sohrabi, M., Sakanlou, F., Tahami, S. A. "Investigating the Effect of Various Fillers on Cohesive Failure Mechanism in Asphalt Mixtures", Periodica Polytechnica Civil Engineering, 64(1), pp. 144-155, 2020. https://doi.org/10.3311/PPci.14505

[10] Kandhal, P. "Waste Materials in Hot Mix Asphalt - An Overview", In: Waller, H. (ed.) Use of Waste Materials in Hot-Mix Asphalt, ASTM International, West Conshohocken, PA, USA, 1993. pp. 3-16. https://oi.org/10.1520/STP19841S a regular trend between increase the additive content and fatigue life in specimens made with limestone aggregates. These two events in the specimens made with the two groups of aggregates illustrated the necessity of economic analysis in the specimens made with different aggregates.

[11] Drochytka, R., Dufek, Z., Michalčíková, M., Hodul, J. "Study of Possibilities of Using Special Types of Building and Demolition Waste in Civil Engineering", Periodica Polytechnica Civil Engineering, 64(1), pp. 304-314, 2020. https://doi.org/10.3311/PPci.15128

[12] Silva, J. A. A., Rodriguez, J. K. G., de Carvalho, M. W., Lucena, L. C. F. L., Cavalcante, E. H. "Mechanical performance of asphalt mixtures using polymer-micronized PET-modified binder", Road Materials and Pavement Design, 19(4), pp. 1001-1009, 2018. https://doi.org/10.1080/14680629.2017.1283353

[13] Ghile, D. B. "Effects of Nanoclay Modification on Rheology of Bitumen and on Performance of Asphalt Mixtures", Master Thesis, Delft University of Technology, 2006. [online] Available at: https://repository.tudelft.nl/islandora/object/ uuid\%3Ae92ae692-10e5-455d-b8ad-0eff3702071e

[14] Hamedi, G. H. "Investigating the Use of Nano Coating Over the Aggregate Surface on Moisture Damage of Asphalt Mixtures", International Journal of Civil Engineering, 16, pp. 659-669, 2018. https://doi.org/10.1007/s40999-016-0143-X

[15] You, Z., Mills-Beale, J., Foley, J. M., Roy, S., Odegard, G. M., Dai, Q., Goh, S. W. "Nanoclay-modified asphalt materials: Preparation and characterization", Construction and Building Materials, 25(2), pp. 1072-1078, 2011.

https://doi.org/10.1016/j.conbuildmat.2010.06.070

[16] Liu, G. "Characterization and Identification of Bituminous Materials Modified with Montmorillonite Nanoclay", PhD thesis, Delft University of Technology, 2011. [online] Available at: https://repository.tudelft.nl/islandora/object/ uuid\%3Abad09af1-fa51-445a-a575-9c429fae54ec

[17] Xiao, F., Amirkhanian, A. N., Amirkhanian, S. N. "Influence of Carbon Nanoparticles on the Rheological Characteristics of Short-Term Aged Asphalt Binders", Journal of Materials in Civil Engineering, 23(4), pp. 423-431, 2011. https://doi.org/10.1061/(ASCE)MT.1943-5533.0000184

[18] Xiao, F., Amirkhanian, A. N., Amirkhanian, S. N. "Long-term ageing influence on rheological characteristics of asphalt binders containing carbon nanoparticles", International Journal of Pavement Engineering, 12(6), pp. 533-541, 2011. https://doi.org/10.1080/10298436.2011.560267

[19] Khattak, M. J., Khattab, H., Rizvi, H. R., Zhang, P. "The impact of carbon nano-fiber modification on asphalt binder rheology", Construction and Building Materials, 30, pp. 257-264, 2012. https://doi.org/10.1016/j.conbuildmat.2011.12.022 
[20] Azarhoosh, A., Abandansari, H. F., Hamedi, G. H. "Surface-Free Energy and Fatigue Performance of Hot-Mix Asphalt Modified with Nano Lime", Materials in Civil Engineering, 31(9), pp. 192199, 2019 https://doi.org/10.1061/(ASCE)MT.1943-5533.0002836

[21] ASTM "C127 - 15 Standard Test Method for Relative Density (Specific Gravity) and Absorption of Coarse Aggregate", ASTM International, West Conshohocken, PA, USA, 2015. https://doi.org/10.1520/C0127-15

[22] ASTM "C128 - 15 Standard Test Method for Relative Density (Specific Gravity) and Absorption of Fine Aggregate", ASTM International, West Conshohocken, PA, USA, 2015. https://doi.org/10.1520/C0128-15

[23] ASTM "D854 - 14 Standard Test Methods for Specific Gravity of Soil Solids by Water Pycnometer", ASTM International, West Conshohocken, PA, USA, 2014.

https://doi.org/10.1520/D0854-14

[24] ASTM "C131 / C131M - 20 Standard Test Method for Resistance to Degradation of Small-Size Coarse Aggregate by Abrasion and Impact in the Los Angeles Machine", ASTM International, West Conshohocken, PA, USA, 2020 https://doi.org/10.1520/C0131_C0131M-20

[25] ASTM "D5821 - 13(2017) Standard Test Method for Determining the Percentage of Fractured Particles in Coarse Aggregate", ASTM International, West Conshohocken, PA, USA, 2017. https://doi.org/10.1520/D5821-13R17
[26] ASTM "D4791 - 19 Standard Test Method for Flat Particles, Elongated Particles, or Flat and Elongated Particles in Coarse Aggregate", ASTM International, West Conshohocken, PA, USA, 2019. https://doi.org/10.1520/D4791-19

[27] ASTM "C1252 - 17 Standard Test Methods for Uncompacted Void Content of Fine Aggregate (as Influenced by Particle Shape, Surface Texture, and Grading)", ASTM International, West Conshohocken, PA, USA, 2017. https://doi.org/10.1520/C1252-17

[28] Moghadas Nejad, F., Geraee, E., Azarhoosh, A. R. "The effect of nano calcium carbonate on the dynamic behaviour of asphalt concrete mixture", European Journal of Environmental and Civil Engineering, 24(8), pp. 1219-1228, 2020. https://doi.org/10.1080/19648189.2018.1456486

[29] Moghadas Nejad, F., Aflaki, E., Mohammadi, M. A. "Fatigue behavior of SMA and HMA mixtures", Construction and Building Materials, 24(7), pp. 1158-1165, 2010. https://doi.org/10.1016/j.conbuildmat.2009.12.025

[30] Control Groups Company "Universal Testing Machines (UTM) software, (4.1)", [computer program] Available at: https://www. controls-group.com/eng/asphaltbituminous-mixture-testing-equipment/introduction-to-universal-testing-machines-utm. php [Accessed: 02 March 2020] 